\title{
Como pensar o capitalismo contemporâneo? Considerações preliminares
}

Recebido: 04.08.20 Aprovado: 10.10 .20

\author{
Fabrício Maciel* \\ \& Patrícia Mattos**
}

\section{capitalismo na ordem do dia}

$\square$ esde a crise financeira de 2008, o capitalismo volta a ter centralidade nos debates da teoria social. Não só são feitas análises sobre o futuro do capitalismo, como também sobre as inter-relações entre as múltiplas crises econômica, política, ecológica e da reprodução social - que assolam diversos países capitalistas ricos. Nesse sentido, é bastante pertinente a colocação de Boaventura de Sousa Santos (2020) sobre o desvirtuamento do sentido etimológico da palavra crise, que presume ser algo excepcional e transitório, e passa a ser, com o advento do neoliberalismo, institucionalizada e normalizada.

A crise sanitária causada pelo coronavírus exacerba e atualiza as críticas feitas por vários intelectuais ao capitalismo contemporâneo. A atual pandemia evidencia a importância do Estado, de políticas públicas sérias e a gravidade da pobreza e das abissais desigualdades sociais do neoliberalismo global, ao mesmo tempo em que abre brechas para se pensar em possibilidades de novos pactos sociais. Intelectuais críticos $^{1}$ têm-se dedicado a discutir alternativas de sociedade para além do experimento neoliberal. Sem dúvida, são relevantes esses esforços para criticar os modos dominantes de viver e vislumbrar outras formas de vida possíveis, contudo, não é objetivo do dossiê que aqui apresentamos fazer análises de conjuntura. Ainda que alguns autores tenham feito referência à pandemia em seus artigos, esse não foi o mote das reflexões, com exceção de Klaus Dörre, que dedica à pandemia uma parte de seu artigo ${ }^{2}$ e de Thomas Kühn, Daniela Gomes Alcoforado e Miriam Leite Farias, que desenvolvem como base de sua análise um estudo empírico realizado no Brasil durante a pandemia. Nossa intenção neste dossiê é propor um debate, a partir de um enfoque histórico-teórico e empírico, sobre as mudanças estruturais do capitalismo contemporâneo e suas múltiplas interpretações. Interessou-nos não só tratar das macro transformações do capitalismo, mais especificamente, daquelas ligadas à lógica do neoliberalismo, da financeirização e da globalização, como também analisar suas especificidades aqui no Brasil.

\author{
* Fabrício Maciel \\ é professor do \\ Departamento de \\ Ciências Sociais \\ da Universidade \\ Federal Fluminense \\ (UFF/Campos dos \\ Goytacazes) e \\ do Programa de \\ Pós-Graduação em \\ Sociologia Política \\ da Universidade \\ Estadual do Norte \\ Fluminense Darcy \\ Ribeiro (UENF). \\ Pesquisador do \\ CNPq, Rio de Janeiro, \\ Brasil. \\ Orcid: 0000-0003- \\ 4553-6223. \\ <macielfabricio@ \\ gmail.com>
}

** Patrícia Mattos

é professora do

Programa de

Pós-Graduação

em História e do

Departamento de

Ciências Sociais da

Universidade Federal

de São João Del-Rei

(UFSJ), Minas Gerais,

Brasil.

Orcid: 0000-0001-

9013-1116.

<pamattos@uol.com. br>.

1. Ver "Dossiê

Boitempo:

coronavírus e sociedade".

2. A versão do dossiê publicada no site da revista <https://periodicos. unb.br/index.php/ sociedade/index> inclui uma tradução de um artigo do 
sociólogo alemão contemporâneo Klaus Dörre, intitulado "Capitalismo de risco. Landnahme, crise bifurcada, pandemia: chance para uma revolução sustentável?".

3. Vale ressaltar que priorizar o debate com as teorias do Atlântico Norte não significa, de modo algum, desconsiderar a importância da produção latinoamericana sobre a nova dinâmica do capitalismo global. No entanto, é inegável que o retorno do capitalismo ao centro das discussões na teoria social tem sido feito, especialmente, por autoras e autores da Europa e dos Estados Unidos.

4. Todas as citações em língua estrangeira são traduções livres dos autores.
Quando elaboramos a proposta deste dossiê, em 2018, percebíamos que as discussões sobre a economia política e o conceito de capitalismo estavam em segundo plano nas reflexões das ciências sociais no Brasil. Um breve olhar sobre os títulos das mesas e Grupos de Trabalho das últimas edições dos congressos da Associação Nacional de Pós-graduação e Pesquisa em Ciências Sociais (Anpocs) e da Sociedade Brasileira de Sociologia (SBS) permitia constatar isso. Enquanto o capitalismo voltava ao centro das preocupações da teoria social no Atlântico Norte ${ }^{3}$, entre nós, isso não acontecia. Foi a partir dessa constatação que nasceu a proposta deste dossiê.

O diagnóstico de crise do capitalismo é feito por renomados economistas como Larry Summers (2014), secretário do Tesouro do governo Bill Clinton e formulador da desregulamentação financeira dos anos de 1990, Joseph Stiglitz (2019) e Paul Krugman, os dois últimos ganhadores do Prêmio Nobel de economia. Os baixos índices de crescimento econômico, a alta concentração de renda nas mãos de $1 \%$ da população mundial, o endividamento geral de governos, famílias, empresas e bancos, as extremas pobreza e desigualdade social constituem fortes indícios da falência do neoliberalismo, da financeirização e da globalização. Thomas Piketty (2014) é outro economista que, com seu livro O capital no século XXI, trouxe para o grande público em vários países, inclusive no Brasil, a discussão sobre os problemas ocasionados quando a taxa de remuneração do capital ultrapassa as taxas de crescimento da produção e da renda, gerando desigualdades sociais insustentáveis que podem colocar em xeque a democracia.

Na teoria social, a crise e o futuro do capitalismo moderno têm sido objeto de ricos debates (Wallerstein et alii, 2013). Como constata Wolfgang Streeck (2016), "o capitalismo sempre foi uma formação social improvável, cheia de conflitos e contradições" (Streeck, 2016: 1) ${ }^{4}$, marcada por uma sucessão de crises, nas quais, para garantir sua sobrevivência, foi forçado a pactuar com transformações profundas em suas instituições sociais e econômicas. Nancy Fraser (2015b; 2018) sintetizou, de forma acurada, essa tendência com sua análise das mudanças nos regimes de acumulação - capitalismo liberal, capitalismo estatalmente organizado, capitalismo neoliberal -, e sua correlação com a desestabilização dos domínios da política e da reprodução social. Ela afirma que um regime encontra dificuldades e limites criando crises que o outro se propõe a resolver ou superar, ao mesmo tempo que tende a gerar contradições que produzirão novas crises, abrindo espaço para o surgimento de outro regime (Fraser, 2018). Se, até o momento, o capitalismo foi capaz de se reinventar, isso não significa que o fará para sempre. E é essa a premissa que inspira as discussões feitas por vários teóricos e teóricas críticos na atualidade. Aliás, essa é a ideia que norteou as teorias da crise do capitalismo 
não só para Marx e Engels, mas também para autores como Ricardo, Mill, Sombart, Keynes, Hilferding, Polanyi e Schumpeter, todos os quais esperaram, de uma forma ou de outra, ver o fim do capitalismo ainda vivos (Streeck, 2016: 3).

Se há certo consenso entre autores e autoras sobre a crise do capitalismo, o mesmo não pode ser dito a respeito de suas causas e de seu desfecho. Encontramos desde abordagens mais estruturalistas, que diagnosticam uma estagnação cada vez mais intensa do sistema capitalista, abrindo espaço para as lutas anticapitalistas, cujo resultado está em aberto, ou ainda as que se aproximam de um marxismo estruturalista, detectando a fraqueza estrutural do capitalismo e sua tendência de superação por algum tipo de socialismo; passando por aquelas que, mesmo identificando as contradições internas que ameaçam o capitalismo, acreditam que a ordem capitalista pode se reinventar a partir de novas formas de governança entre Estados, empresas e sociedade civil (cf. Wallerstein et alii, 2013); até aquelas nada otimistas, como a de Streeck (2016), que vê o capitalismo democrático em risco, sendo substituído por um "interregno duradouro", caracterizado pela desordem social, incerteza e indeterminação.

A tese de Streeck é que, mesmo se admitindo que a relação entre capitalismo e democracia tenha sido sempre permeada por tensões e conflitos distributivos, estes não encontram mais condições de solução adequadas sob a égide das destruições institucionais causadas pelo neoliberalismo (Streeck, 2016; 2018). Desde o final da Segunda Guerra até a década de 1970, período conhecido como "era de ouro", havia espaço para discussões que atrelavam o capitalismo ao progresso social, ao pleno emprego, à seguridade social e ao fim da pobreza material, ideias que não mais são vistas como necessárias e incontestáveis. Em outras palavras, durante um bom tempo, houve acordo em torno da percepção de que uma economia capitalista saudável precisava de crescimento constante, moeda estável e garantia de certos benefícios sociais para os desprovidos de capital. Isso mudou substantivamente com o neoliberalismo global; o ativismo político do Estado intervencionista, que mediava os conflitos distributivos, foi substituído pela dinâmica do Estado em prol do mercado. Ademais, estabeleceu-se uma "crise financeira permanente", que serve para legitimar cortes de salários e gastos sociais, não tendo como objetivo o seu desenlace (Santos, 2020).

Segundo Streeck, o conflito de classes, nos dias de hoje, é estabelecido entre as classes que são "dependentes do trabalho" e as que são "dependentes de lucro" (Streeck, 2018), ainda que frações da classe média possam fazer parte dessas duas classes, mesmo se não ditam as regras do jogo. As condições de assimetria de poder são gritantes devido à concentração de renda nas mãos de $1 \%$ da população 
5. Para uma síntese desse círculo vicioso, ver texto de Streeck "Como vai acabar o capitalismo. O epílogo de um sistema em desmantelo crônico", disponível em <https://piaui.folha. uol.com.br/materia/ como-vai-acabaro-capitalismo/>. Acesso em: 01 Ago. 2020. mundial, num capitalismo financeirizado, que não estimula o investimento dos capitalistas em atividades produtivas, caracterizado por baixo crescimento econômico, endividamento de Estados, empresas, famílias e bancos, além de altos índices de desigualdade social. Esses aspectos criam um círculo vicioso que aponta para a crise do sistema capitalista. Cresce, entre os especialistas, a percepção de que o aumento das desigualdades sociais está relacionado ao baixo crescimento econômico, já que a desigualdade cria obstáculos para melhorias na produtividade, além de afetar diretamente o consumo. Ao mesmo tempo, o baixo crescimento retroalimenta as desigualdades sociais, uma vez que radicaliza a luta por recursos escassos, sendo cada vez mais custoso para as elites do capitalismo global negociar benefícios para aqueles sem capital. Por fim, o endividamento geral aumenta as desigualdades sociais a partir das políticas de austeridade que reduzem salários e gastos sociais, diminuindo a capacidade de compra de famílias e indivíduos, colocando-os como reféns da lógica nefasta da financeirização ${ }^{5}$.

O interregno duradouro do qual fala Streeck (2016) ocorre pelo colapso da integração sistêmica.

O capitalismo contemporâneo pareceria então ser uma sociedade cuja integração sistêmica está crítica e irremediavelmente enfraquecida, de modo que a continuação da acumulação do capital - por um período de duração incerta - se torna unicamente dependente do oportunismo de indivíduos individualizados coletivamente incapacitados, que lutam para proteger a si mesmos de acidentes iminentes e pressões estruturais em seu status social e econômico. Subgovernado e subadministrado, o mundo social do interregno pós-capitalista, nos rastros da eliminação dos Estados, governos, fronteiras, sindicatos e outras forças moderadoras efetuada pelo capitalismo neoliberal pode a qualquer momento ser atingido por desastre; por exemplo, bolhas implodindo ou violência penetrando a partir de uma periferia colapsando em direção ao centro. Com indivíduos privados de defesas coletivas e deixados à sua própria sorte, o que resta da ordem social depende da motivação de indivíduos para cooperarem com indivíduos numa base ad hoc, dirigidos por medo, ganância e interesses básicos na sobrevivência individual. Visto que a sociedade perdeu a habilidade de dar aos seus membros proteção efetiva e modelos provocados para ação social e existência social, indivíduos só podem confiar em si mesmos enquanto a ordem social depende no modo mais fraco possível da integração social, Zweckrationalität. (Streeck, 2016: 14).

Streeck não é, de modo algum, o único teórico social que vê a crise da democracia como resultado do advento do capitalismo neoliberal. Colin Crouch (2011), Wendy 
Brown (2006), Stephen Gill (1998) e Nancy Fraser (2018) também endossam essa tese. Cada um desses autores e autoras, a seu modo, destaca alguns aspectos que configuram a crise da democracia. Em resumo, podemos caracterizá-la como:

i. descrença da população na política partidária e o clamor por uma política antissistema;

ii. incapacidade dos Estados resolverem os conflitos sociais e sua tendência a operarem de acordo com os ditames do mercado;

iii. apreensão do poder político por empresas oligopolistas;

iv. obstrução democrática típica do "novo constitucionalismo", que difunde a política macroeconômica neoliberal transnacionalmente, através de tratados internacionais e instituições como Banco Mundial, Organização Internacional do Trabalho (OIT), Fundo Monetário Internacional (FMI), os bancos centrais e as agências de classificação, que passam a definir as políticas macroeconômicas para os Estados;

v. crescimento da extrema direita radical, com sua intolerância à diversidade cultural e tradicionalismo, xenofobia, discurso anti-imigração, dentre outros; e

vi. enfraquecimento dos partidos de esquerda.

Ao buscar ir além de Streeck, Crouch (2011), Brown (2006) e Gill (1998), Fraser (2015a, 2015b, 2018) desenvolve sua teoria sobre as crises do capitalismo demonstrando que o capitalismo não só é o principal vetor da crise política, como também das crises da reprodução social e ambiental. Inspirada em Polanyi, Fraser afirma que a tendência à crise do capitalismo não é só interna ao sistema econômico, mas está, sobretudo, relacionada à sua propensão para desestabilizar a sociedade e a natureza com a crescente mercantilização não regulamentada dos domínios não econômicos. Como já foi dito, não existe concordância entre autores e autoras sobre o futuro do capitalismo. Fraser, ao contrário de Streeck, vê potencialidades de lutas contra-hegemônicas, tendo mesmo publicado, junto com Cinzia Arruzza e Tithi Bhattacharya, Feminismo para 99\%: Um manifesto (2019), conclamando por uma luta feminista anticapitalista, ecossocialista, antirracista e internacionalista. No Manifesto, as autoras afirmam a necessidade de virada do movimento feminista, do feminismo liberal, cuja pauta está centrada no reconhecimento de mulheres de classe média e alta que alcançam postos de prestígio no mercado de trabalho e legitimam toda a ideologia meritocrática, para uma ampla luta que envolva não só uma grande diversidade de mulheres, mas também os movimentos progressistas que combatem as diferentes formas de opressão e violência na sociedade capitalista. 
Se, até aqui, procuramos apresentar o contexto de ressurgimento das teorias da crise do capitalismo, a seguir, faremos uma exposição sobre as suas mudanças estruturais desde a década de 1970, recuperando aspectos centrais da economia política, da moralidade e da cultura do experimento neoliberal.

\section{A mudança estrutural do capitalismo contemporâneo e a atualidade da condição periférica}

Nesta seção procuraremos reconstruir algumas das principais transformações estruturais do capitalismo contemporâneo. Como "contemporâneo", gostaríamos de definir o capitalismo que se estrutura em escala global a partir da década de 1970. Para alguns dos principais autores e autoras aos quais recorreremos com este objetivo, é neste período que podemos identificar o início de algumas das principais mudanças estruturais que procuraremos tematizar aqui e que vão permitir um diálogo com a multiplicidade de interpretações atuais do capitalismo que apresentaremos na parte final.

Para toda uma geração de intelectuais, dentre os quais se incluem Claus Offe, Ulrich Beck, André Gorz, Robert Castel, Nancy Fraser, Axel Honneth, Boltanski e Chiapello, bem como Richard Sennett, dentre outros, é na década de 1970 que podemos

6. Na América Latina e no Brasil, a percepção dos limites do capitalismo em promover a justiça social se encontra no cerne de inúmeros estudos teóricos e empíricos da teoria da dependência em autores como Celso Furtado, Raul Prebisch, Florestan Fernandes, Fernando Henrique Cardoso, Teotônio dos Santos, dentre outros. Para toda essa tradição de estudos entre nós, a condição periférica estrutural diante do Atlântico Norte deveria ser o primeiro aspecto teórico e político a ser enfrentado para a busca de um capitalismo menos injusto. identificar uma ruptura de algumas estruturas do capitalismo global que pareciam oferecer caminhos para a construção de um capitalismo social, capaz de produzir o que deveria ser seu principal objetivo, ou seja, a construção de um padrão de justiça social que protegesse todas as classes da vulnerabilidade social ${ }^{6}$.

Nesta direção, a constatação do fracasso do Welfare State nos Estados Unidos e em países centrais da Europa como Inglaterra, França e Alemanha se coloca como o principal fato histórico divisor de águas para uma nova interpretação estrutural do capitalismo global contemporâneo. Portanto, gostaríamos de tomar este fato como principal mote de nossa análise a partir de agora. Diante da leitura de autores como Robert Castel (1998), pensando o caso francês, e Ulrich Beck (2007), a partir do caso alemão, nosso argumento é que o fim do Welfare State em países do coração do capitalismo é a principal prova de que a promoção da justiça social no contexto do neoliberalismo vai se tornando, cada vez mais, de difícil realização ou até mesmo utópica. Ou seja, a construção de um capitalismo social, como tematizou, por exemplo, Richard Sennett (2015), é uma utopia quase irrealizável, se prestarmos detida atenção à história recente deste sistema em suas dimensões políticas econômicas e sociais.

O desafio de pensar o capitalismo desta forma, ou seja, enquanto sistema explicitamente fracassado há 50 anos na tentativa de promover justiça social, nos coloca 
outro desafio central para o enfrentamento de nosso objetivo aqui. Partimos do pressuposto de que o fracasso do capitalismo social nos países centrais é o principal dado empírico para uma reinterpretação radical do sistema por considerar que nos países periféricos, ou semiperiféricos como o Brasil, o capitalismo nunca promoveu a justiça social. Ou seja, não é a história do fracasso do capitalismo na periferia que nos mostrará as verdadeiras razões de sua incapacidade intrínseca na promoção da justiça, mas sim a história de sua totalidade global enquanto sistema socialmente injusto.

Sustentamos este argumento por considerar que, até o período dos "Trinta anos gloriosos", ou seja, o Welfare State desenvolvido a partir do final da Segunda Guerra Mundial e que dura até a década de 1970, ainda havia alguma esperança de que o capitalismo poderia promover a justiça social e generalizá-la para todo o mundo (Castel, 1998; Streeck, 2016; 2018). Na precisa definição de Robert Castel (1998), o Welfare State significava quase pleno emprego no plano econômico, além de seguridade e segurança na vida social. Ou seja, para todos os autores analisados aqui a ruptura deste pacto significa o fracasso do capitalismo e provoca de imediato a análise do fim ou das profundas modificações da sociedade do trabalho no sentido mais marxista do termo?.

Não avançamos com esta análise se não problematizarmos de imediato a relação assimétrica entre centro e periferia, ou seja, como os países centrais, ao longo do século XX, generalizaram para fora todos os problemas sociais, ambientais, políticos e econômicos produzidos pelo sistema em sua totalidade, enquanto de alguma forma buscaram proteger seus territórios e sua sociedade desses riscos. Para tanto, precisamos romper com o que Ulrich Beck (2008) muito apropriadamente definiu como "nacionalismo metodológico". Com este conceito, o autor procurou tematizar o paradigma que dominou as análises da desigualdade social ao longo do século XX restringindo-as aos marcos cognitivos e políticos das sociedades nacionais. Ou seja, o que o autor está dizendo é que se montou e se reproduziu sistematicamente uma forma de compreender os rumos do capitalismo e seus efeitos negativos dentro do esquadro das histórias nacionais e da atuação do Estado nacional, ignorando-se ou colocando-se em segundo plano as estruturas globais de reprodução do sistema8.

Recentemente, Stephan Lessenich (2018) problematizou um aspecto essencial desta questão de maneira muito apropriada, definindo como "externalização" todo o processo no qual países centrais, como a Alemanha, na história recente do capitalismo, conseguiram projetar para fora de seus territórios todos os riscos produzidos em escala global. Como exemplo, o autor destaca o crime ambiental, social e político cometido na "tragédia" de Mariana e que se repetiu em Brumadinho e
7. Vale ressaltar aqui que nenhum dos autores analisados, como Robert Castel ou Ulrich Beck, está defendendo que o Welfare State foi um sistema social perfeito. É de amplo conhecimento no debate europeu a inclusão relativa de minorias em seus contextos nacionais, como o caso dos turcos na Alemanha e dos argelinos na França. A questão dos imigrantes sempre foi o calcanhar de Aquiles no Atlântico Norte, mesmo durante os "anos dourados". Sem falar que, nos Estados Unidos, além de ser problemática a inclusão dos imigrantes, sob a égide do Welfare State, foram excluídos "[...] trabalhadores domésticos e agrícolas, privando assim, de fato, muitos negros estadunidenses de direitos sociais" (Fraser, 2015b: 124).

8. É importante lembrar que a reestruturação global do capitalismo, desde os anos de 1970, indica uma decadência relativa de nações centrais e a ascensão de potências como a China, bem como o fortalecimento econômico de nações do chamado Cone Sul do mundo, no qual presenciamos em contexto recente a articulação dos Brics, agora afetada pela atual conjuntura, e o 
potencial produtivo de vários países asiáticos.

9. No final da carreira, Ulrich Beck (2018) vai tematizar a "sociedade global de risco", não se restringindo apenas às suas conhecidas análises sobre a Europa. em inúmeros outros lugares do território periférico global. Nestes crimes, tratados pela mídia eufemisticamente como "tragédias" ou "desastres", vemos com clareza a ação de grandes empresas globais, sediadas em sua grande maioria no Atlântico Norte, sendo poupadas e isentas de responsabilidade pela ausência de uma estrutura jurídica transnacional que possa tematizar de fato o que ocorreu.

Retomemos Ulrich Beck. Cabe ressaltar que ele é um dos principais autores europeus que, de alguma forma, ainda que ambiguamente, tematizou a "periferia" do capitalismo em suas análises ${ }^{9}$. Quando revisamos a obra de autores dentre os mais críticos como, por exemplo, Robert Castel, podemos perceber que mesmo estes, em alguma medida, reproduzem um certo "europeísmo metodológico" em suas investigações, ainda que possamos aprender bastante com elas. Conhecido desde a década de 1980 por seu clássico Sociedade de risco (Beck, 1986), Ulrich Beck na verdade vai adentrar no tema do capitalismo global em um de seus livros posteriores, intitulado Schöne neue Arbeitswelt (2007) (uma tradução aproximada poderia ser "Admirável novo mundo do trabalho"). É neste trabalho que ele vai desenvolver a conhecida e controversa tese da "brasilização do Ocidente", sobre a qual vamos agora nos debruçar brevemente.

Ao visitar o Brasil, nos anos de 1990, o intelectual alemão ficou impressionado com a especificidade de nossa modernização, tendo como aspecto principal a dimensão estrutural do trabalho precário. Isso levou Ulrich Beck a afirmar de imediato que o futuro de países como a Alemanha poderia ser visto especialmente no Brasil. Esta perspectiva do autor, que vai fundamentar a tese da brasilização do Ocidente, precisa ser contextualizada em um cenário europeu que agora lamenta profundamente a perda da principal realização do capitalismo em sua história, ou seja, a construção de um Welfare State que agora não existe mais como antes. Mesmo ao considerar que as condições de vida - incluindo infraestrutura, serviços, segurança, dentre outros aspectos -, em um país como a Alemanha ainda sejam hoje infinitamente melhores do que as do Brasil, o ponto em questão é a percepção de um mundo globalizado em mudança. O que autores como Ulrich Beck e Robert Castel estão percebendo, neste exato momento, é que o capitalismo, que já é um sistema-mundo há cerca de 500 anos, como muito bem definiu Immanuel Wallerstein (1976), agora não consegue mais preservar seus países centrais de suas realizações negativas, até então relegadas aos países periféricos. A partir da leitura destes autores podemos afirmar que esta é a principal mudança estrutural do capitalismo desde a Segunda Guerra Mundial, tanto na dimensão da economia política como nos planos da moralidade e da cultura.

Não por acaso, a tese da brasilização do Ocidente, ancorada especialmente no fato empírico da chegada do trabalho precário e informal aos países centrais da Europa, 
sendo este um dos pilares centrais do ocaso do Welfare State, situa-se na teorização mais ampla de Ulrich Beck sobre a sociedade de risco. O que o autor está percebendo é que os riscos da sociedade global, produzidos pelo capitalismo, são agora compartilhados também pelos países centrais que, durante os anos dourados do Estado de bem-estar social, apenas usufruíram das realizações positivas que o sistema nunca conseguiu generalizar para a periferia.

Entretanto, apesar desta mudança estrutural profunda, que não se restringe aos aspectos da atual conjuntura autoritária, nem aos erros da esquerda ou de algum partido político, as diferenças empíricas entre países centrais e periféricos ainda são evidentes a qualquer observador atento. O aprofundamento da indignidade das condições objetivas e das relações de trabalho e do abandono das classes pauperizadas no Brasil atual, tendo a reforma trabalhista como seu principal marco simbólico, não se explica simplesmente por erros políticos da conjuntura anterior ${ }^{10}$. Para uma compreensão minimamente razoável do momento atual, que não se restrinja às ilusões e à pobreza do apressado debate em torno da conjuntura, precisamos fazer uma reconstrução histórica sobre as mudanças estruturais do capitalismo. Continuaremos este exercício no próximo tópico, tematizando a questão da vulnerabilidade social e sua relação com uma nova dominação tecnológica que parece se estabelecer no mundo atual.

\section{A economia política do capitalismo contemporâneo: vulnerabilidade social e dominação tecnológica}

Neste tópico, procuraremos levantar dois aspectos essenciais da economia política do capitalismo atual e para tanto recorreremos especialmente às obras de dois autores conhecidos no debate brasileiro: Robert Castel e André Gorz. A primeira questão que se coloca e que enfrentaremos especialmente a partir da obra de Castel é o problema da vulnerabilidade social. Richard Sennett (2015) também vai enfrentar esta questão central do capitalismo contemporâneo com o conceito de "descartabilidade". Entretanto, a obra de Castel parece ser aquela que enfrenta teoricamente, de maneira mais precisa e profunda, o problema. Em seu clássico livro Metamorfoses da questão social: uma crônica do salário (1998), o autor faz uma reconstrução do que ele define como o fim da sociedade salarial. Com isso, ele está se referindo ao fim do Welfare State e procurando compreender seu período posterior, assim como Ulrich Beck.

Nesta direção, a principal constatação de Castel vai ser sobre a produção inédita, no contexto europeu, pensando especialmente a partir do caso francês, do que ele vai chamar de "sobrantes", ou seja, pessoas totalmente vulneráveis e descartáveis diante
10. A reforma trabalhista, aprovada no governo Temer, o que é amplamente de conhecimento público, levou a cabo a desconstrução de uma série de direitos históricos do trabalho no Brasil, o que tem sido ampliado pelo governo atual, com uma série de medidas, como a "minirreforma" de 2019 (a MP da liberdade econômica), o que apenas dificulta o caminho para a construção de um novo pacto social. 
11. Aqui adaptamos a provocativa definição de Jessé Souza (2003) de uma ralé estrutural como elemento central para a compreensão da desigualdade em contextos periféricos como o brasileiro. $\mathrm{O}$ ponto em questão é que a ralé agora também está presente no centro e com isso exige uma reinterpretação do capitalismo em sua totalidade. do mercado de trabalho, agora cada vez mais informal e precarizado. Para Castel, os "sobrantes" são produto de uma lógica de mercado que expulsa um número cada vez crescente de trabalhadores sem criar possibilidades de reinserção para essas pessoas. A estes soma-se uma juventude que não terá chances de inserção ou cujas chances são cada vez mais de uma inserção precária e indigna. Castel com isso vai cunhar o conceito de "desfiliação social", em oposição ao conceito elástico e impreciso de "exclusão", para tematizar especialmente este fenômeno no qual um número cada vez maior de europeus, a partir dos anos de 1970, vai compor o que ele define como "zona de vulnerabilidade" tanto do mercado como da vida social (Castel, 1998).

Esta nova realidade, presente desde sempre na periferia do capitalismo, vai criar agora uma espécie de "ralé global"11, composta tanto por europeus pauperizados como pela presença crescente e incômoda de imigrantes. Este dado empírico se apresenta como central e vai definir o incômodo de intelectuais como Robert Castel, Ulrich Beck, Claus Offe e André Gorz, dentre outros, no sentido de procurar agora tematizar esta nova fase "pós-Welfare State" e todos os seus dilemas. Nas precisas palavras de Ulrich Beck (2007), a Europa presencia agora uma fratura no elo entre democracia, economia e vida social, ou seja, o pilar do Welfare State do qual a esfera pública europeia tanto se orgulhava. Para Claus Offe (1994), em sua precisa definição de um "capitalismo desorganizado", a chegada do trabalho informal e ilegal na Europa nos permitiria questionar se o trabalho ainda seria uma categoria central para se compreender as sociedades atuais, debate este conhecido no Brasil através da obra de Ricardo Antunes (2000).

Este novo momento do capitalismo e das sociedades europeias vai ser tematizado também por outros autores mais recentes como, por exemplo, na interessante definição de Oliver Nachtwey (2016), que vai chamar o momento atual de "modernidade regressiva", em comparação com a "modernidade social" dos 30 anos gloriosos. Em todas estas perspectivas podemos perceber um certo pessimismo e saudosismo diante de um período áureo que parece não poder mais existir. Para Castel, a ruptura do pacto salarial, ou seja, o elo social mais estável e seguro das sociedades do Welfare, é o principal dado empírico que vai explicar o fim das sociedades salariais (o que não significa o fim das sociedades do trabalho, como para Claus Offe, por exemplo). Um salário fixo, regular e garantido, neste sentido, foi a base econômica fundamental para a estabilidade das sociedades europeias durante os 30 anos gloriosos como um todo. Não por acaso, uma das características mais marcantes do capitalismo atual, até mesmo nas nações centrais, é a ausência de um salário fixo e garantido para grande parte da população. Este é um aspecto decisivo de toda a desconstrução que vem sendo levada a cabo em escala global nos últimos 50 anos, e que vai ser obviamente mais profunda nos países periféricos. 
A esta altura já podemos entrar no segundo problema que gostaríamos de levantar neste tópico: o surgimento e o estabelecimento de uma dominação tecnológica inédita na história do capitalismo. Uma característica central do novo contexto marcado pela ausência de salários fixos e pelo aprofundamento da precariedade e da indignidade do trabalho em escala global é exatamente o papel que a tecnologia exerce em nossas vidas e, para sermos mais precisos, as possibilidades de dominação e de reprodução da desigualdade que as tecnologias oferecem às grandes empresas.

Um dado recente mostrou que a Uber, o 99, o Rappi e o I-Food juntos já são quem mais emprega no Brasil, totalizando quase 4 milhões de trabalhadores com empregos precários ${ }^{12}$. Este dado é bastante sintomático do processo que já tem sido definido como a "uberização" do capitalismo global ${ }^{13}$. Também é emblemático e grave o fato de que empresas - como a Uber - não se caracterizam como empregadores e estão protegidas por um formato jurídico que dificulta a caracterização como tal. Ou seja, um aplicativo que emprega precariamente milhões de pessoas no mundo inteiro se apresenta como "parceiro" e "facilitador" de relações sociais, quando, na verdade, é um empregador invisível, impessoal, distante e intocável. Não há na história do capitalismo alguma forma de dominação social mais eficaz e cruel do que essa. Todo o custo, a responsabilidade e o sofrimento ficam a cargo do próprio trabalhador, chamado eufemisticamente e de forma irônica de "colaborador", "parceiro" e "autônomo". Estamos lidando aqui com um processo de radicalização profunda do que Robert Castel vai chamar de "individualismo negativo", em um contexto no qual as pessoas mais vulneráveis são abandonadas à sua própria sorte, rendendo milhões em lucro para os invisíveis gigantes da tecnologia. Neste exato momento, em plena pandemia, no qual escrevemos este texto, a questão dos entregadores se coloca talvez como o principal exemplo empírico desta trágica realidade ${ }^{14}$.

Para pensar as razões pelas quais a tecnologia, a criação de um mecanismo de poder tão importante no mundo atual, a obra de André Gorz apresenta algumas reflexões de grande importância. Não vamos adentrar aqui no já conhecido debate de como as tecnologias têm influenciado resultados de eleições e manipulado a opinião pública no Brasil e no mundo. A obra de Gorz nos mostra uma mudança estrutural decisiva na economia política do capitalismo contemporâneo através de sua análise de como o conhecimento tecnológico se torna a principal força produtiva atual. Gorz ficou conhecido nos anos de 1980 com seu clássico Abschied vom Proletariat (1980), no qual levanta a polêmica tese, incômoda ao marxismo, sobre as razões do fracasso do socialismo e como o capitalismo teria vencido enquanto sistema social.
12. Ver: <https:// exame.com/ economia/appscomo-uber-e-ifoodsao-fonte-de-rendade-quase-4-milhoesde-pessoas/>. Acesso em: 26 Ago. 2020.

13. Ver, por exemplo, o livro de Tom Slee (2019), Uberização: a nova onda do trabalho precarizado.

14. O último filme de Ken Loach (2019) "Você não estava aqui", é belíssimo ao ilustrar esta triste realidade. 
Ao avançar, especialmente com seus livros posteriores Misérias do presente, riqueza do possível (2004) e O imaterial (2005), Gorz desenvolve a tese que mais nos interessa aqui, ou seja, a de que o conhecimento se torna uma força produtiva sem precedentes, e especialmente o conhecimento tecnológico. Não por acaso, o autor vai definir o período atual de "pós-fordismo" como uma "sociedade do conhecimento" ou "sociedade do imaterial" (Gorz, 2004; 2005). A análise do autor é de fundamental importância pois permite compreender funcionalmente como o mundo empresarial vai se reorganizar através da tecnologia. Toda a reestruturação produtiva que ocorre no capitalismo global desde a década de 1970 pode assim ser compreendida antes de tudo como "reestruturação tecnológica". Sem o domínio de tecnologias específicas seria impossível, por exemplo, o processo de terceirização e informalização do capitalismo, protegendo algumas "empresas mães", nos termos de Gorz, enquanto a maioria das atividades vai ser precarizada em uma lógica de "terceirização em cascata" (Gorz, 2004).

O ponto nodal aqui é que os grupos empresariais centrais só conseguem manter o seu poder e controle sobre os "parceiros" através da posse de tecnologias específicas que não são democratizadas. Além disso, atualizando a análise de Gorz, os gigantes da tecnologia como Amazon, Google e Facebook são os que mais lucram especialmente na atual crise de pandemia do Covid-19, em um contexto que já tem sido definido como "capitalismo digital". Com isso, os trabalhadores "digitais" na base do sistema não possuem nenhum direito, garantia ou proteção. Neste contexto, em países como o Brasil ter um salário razoável fixo e garantido já se tornou privilégio da classe média alta. Este cenário de generalização da condição de descartabilidade, com isso, é o contrário de qualquer ideia de Welfare State e pacto social. Mais recentemente, Randall Collins (2013) diagnosticou que a ascensão da inteligência artificial fará com a classe média o que a mecanização fez com a classe trabalhadora manufatureira, gerando um amplo quadro de desemprego para uma classe que fez todas as suas apostas na educação como forma de escapar do destino "redundante" dos trabalhadores. Esse desemprego colocará em risco o estilo de vida dessa classe que ratifica toda a ideologia do capitalismo com sua crença no trabalho duro, diversão intensa e consumismo. Só que, longe de ver esse processo de forma desesperançada, Collins vislumbra o declínio do capitalismo e as potencialidades do socialismo.

Na próxima seção procuraremos mostrar como as dimensões da moralidade, da ideologia e da cultura surgem no debate recente, em complemento à dimensão da economia política, formando assim um breve panorama geral das interpretações contemporâneas sobre o capitalismo. 
Moralidade, ideologia

e cultura do capitalismo contemporâneo

No cenário da teoria crítica recente, destaca-se a obra magna de Axel Honneth (2015), seu livro O direito da liberdade, no qual o autor vai dedicar uma parte inteira à reconstrução da relação entre moralidade e mercado. Para o autor, a moralidade pode ser definida como um conjunto de interações éticas que precedem as relações de troca instrumentais no mercado (Honneth, 2015). Com isso, o autor chama a atenção para o significado que perpassa qualquer relação social no plano da economia política. Na perspectiva de seu funcionalismo normativo, Honneth procura com isso fazer uma atualização normativa das relações de mercado a partir da lógica da moralidade.

Ao concordar com outros autores de sua geração e recorrendo em vários momentos, por exemplo, à obra de Robert Castel, Honneth vai ratificar com o diagnóstico de que, a partir dos anos de 1970, com a ruptura do Welfare State, presenciamos um novo momento na história do capitalismo contemporâneo, que ele vai definir como marcado patologicamente por um contexto de anomia. Neste cenário, a plena realização da liberdade social ${ }^{15}$, o que seria o objetivo maior das sociedades ocidentais, seria impedida nas esferas do mercado, da política e das relações pessoais. Ao pensar especialmente na esfera do mercado e recorrendo a toda uma tradição de autores como Hegel, Durkheim, Parsons e Polanyi, Honneth vai mostrar que o mercado poderia ser uma esfera de produção da liberdade social, se historicamente não tivesse se transformado em um reino de relações patológicas e anômicas, definidas pela não liberdade de todas as partes envolvidas nas trocas da economia de mercado ${ }^{16}$.

Com isso, a obra de Honneth nos permite compreender como ocorre a atualização da "moralidade do capitalismo", ou seja, como as interações éticas e os julgamentos de valor das sociedade atuais se transformam a partir da década de 1970, caminhando no sentido da consolidação de uma moralidade que parece cada vez mais profundamente meritocrática. Neste sentido, é muito interessante a análise feita por Sighard Neckel, tomando emprestado um conceito de Habermas, sobre o atual processo de "refeudalização" do capitalismo (Neckel, 2016). Por fim, também na esfera do consumo, Honneth vai identificar uma carência de precondições institucionais que poderiam transformá-la em uma instituição que proporcionasse a liberdade social. Por fim, o autor vai apostar em uma "recivilização moral" da economia de mercado, o que dependeria do fortalecimento de comunidades internacionais com poder de veto e com o apoio da opinião pública, para impor impedimentos objetivos aos mecanismos de desregulação do mercado.

15. Para reavivar a práxis ética,

Honneth se propõe a identificar as anomias e patologias sociais que comprometem a liberdade social, o que significa fazer dos interesses e das necessidades do outro condição para a própria liberdade.

16. Sua análise nos permite pensar, por exemplo, em como o atual contexto autoritário e de intolerância se conforma em um conjunto de interações éticas que radicalizam e justificam a lógica predatória das relações do capitalismo no plano da economia política. 
Outro livro que é um marco nesta discussão é O novo espírito do capitalismo, de Boltanski e Chiapello (2009). Apesar de conhecida no Brasil, a obra de Boltanski tem sido muito mais discutida no plano mais abstrato da teoria social, considerando sua discussão sobre o que é crítica social, do que propriamente na dimensão de um debate sobre capitalismo, o que é de fato o problema central do livro. Embasados em ampla pesquisa empírica, a comparar as mentalidades dos executivos nos anos de 1960 e 1990, os autores desenvolveram a importante noção de "terceiro espírito do capitalismo". Para tanto, revisitando as obras de alguns clássicos e fazendo uma ampla descrição analítica das transformações da sociedade de classes na França no contexto posterior à Segunda Guerra Mundial, os autores vão definir três momentos e três consequentes "espíritos" do capitalismo, recorrendo assim à clássica noção de Max Weber.

O primeiro espírito seria aquele descrito por Werner Sombart, ou seja, situado no final do século XIX, que coloca no epicentro a figura do burguês empreendedor e a descrição dos valores burgueses. Assim, a figura do empreendedor, do capitão de indústria e do conquistador concentram elementos heroicos da descrição, pondo ênfase no jogo, na especulação, no risco e na inovação (Boltanski \& Chiapello, 2009).

O segundo espírito é aquele que se consolida entre as décadas de 1930 e 1960, colocando a ênfase muito mais na organização em si do que no empresário individual. Este tem como figura heroica o executivo que, mais do que os acionistas, leva a cabo os interesses gerais da empresa e sua consolidação. O segundo espírito também encarna o ideal cívico das empresas, em seu papel na promoção da justiça social ao lado do Estado.

O terceiro espírito, em contrapartida, que se esboça a partir dos anos de 1970 e se mostra em toda nitidez nos anos de 1990, é aquele que vai valorizar o trabalho em equipe e as iniciativas coletivas nas cidades por projetos, apagando a figura da dominação, da autoridade e da hierarquia social, encarnada com todo vigor no grande executivo do segundo espírito. O terceiro espírito com isso apresenta forte teor ideológico, escondendo um capitalismo altamente hierarquizado que radicaliza sua dominação e a consequente desigualdade entre as classes. Não por acaso, o conceito de ideologia utilizado remete-se a Louis Dumont, para quem a ideologia constitui um conjunto de crenças compartilhadas, inscritas nas instituições, comprometidas em ações e, exatamente por isso, ancoradas no real. Ou seja, esta noção de ideologia envolve a tematização da busca por legitimação e engajamento que o capitalismo precisa realizar para ter seu ancoramento em indivíduos de carne e osso.

Além disso, Boltanski e Chiapello apresentam uma definição de capitalismo bastante pertinente, compreendendo este sistema como baseado na exigência de acumu- 
lação ilimitada de capital mediante meios formalmente pacíficos ${ }^{17}$. Esta definição é interessante para pensarmos como o capitalismo hoje é um sistema que administra o caos e um conjunto de crises, especialmente agora, no contexto da pandemia. Por fim, na precisa definição dos autores, o espírito do capitalismo seria a ideologia que justifica o compromisso com o sistema. Ou seja, este espírito seria um conjunto de crenças associadas à ordem capitalista que contribuem para justificar tal ordem e manter, legitimamente, os modos de ação e as disposições coerentes com ela. Ao pensarmos o cenário atual, podemos dizer que, com isso, o terceiro espírito ao mesmo tempo incentiva a iniciativa individual no mercado e corrobora a intervenção autoritária do Estado, de modo a legitimar uma ordem desigual ainda mais profunda do que em períodos anteriores.

Por fim, Richard Sennett vai se debruçar sobre o tema, procurando compreender este período que ele define como "novo capitalismo", o que coincide com nossa definição de "capitalismo contemporâneo". O principal aspecto de sua obra se concentra exatamente nos danos pessoais causados por esta nova ordem, que ele vai apropriadamente definir como "corrosão do caráter" (Sennett, 2006). Para o cientista social norte-americano, o principal aspecto da nova cultura capitalista é a ideologia do trabalho em equipe, que, na verdade, esconde as verdadeiras estruturas rígidas do sistema. Neste sentido, o ideal da flexibilidade sugere uma disposição individual, elogiada como uma "habilidade", e que, com efeito, coloca os indivíduos totalmente à disposição dos interesses empresariais.

No contexto da obra de Sennett, podemos compreender a cultura em sentido prático, ou seja, no sentido da cultura cotidiana que é desenvolvida no interior do mundo empresarial, especialmente pelas grandes corporações. Para o autor, esta cultura corrói o caráter individual no sentido de destruir as capacidades individuais para construir laços duradouros. Em termos simples, o indivíduo que muda de empresa constantemente não estabelece vínculos sólidos em nenhum lugar, o que mina a resistência e a organização de classe. O caráter aqui não deve ser compreendido no sentido da boa-fé de uma pessoa, mas sim como um conjunto de habilidades para a solidariedade e a ação coletiva. Esta compreensão se afina com a noção de individualismo negativo de Robert Castel, com a qual vão concordar também Ulrich Beck e Axel Honneth, ao mostrar que, no fundo, os indivíduos são atomizados e abandonados à própria sorte.

Como consequência, Sennett (2015) vai perceber que uma das características centrais deste novo capitalismo é a ampliação do "fantasma da inutilidade", até mesmo para as classes médias, mais uma vez afinado com Castel, que vai definir o mesmo contexto com a noção de "zona de vulnerabilidade". Ambos estão perceben-
17. Boltanski avança com sua análise sobre capitalismo, ao lado de Arnaud Esquerre, com a ideia de uma "economia do enriquecimento" (Boltanski \& Esquerre, 2020).

Entretanto, sua obra clássica, que aqui analisamos, apresenta uma validade analítica que não se restringe a aspectos específicos da conjuntura póscrise de 2008. 
do sistematicamente a construção de um cenário de naturalização da condição de descartabilidade em países centrais do capitalismo, o que nunca foi novidade na periferia.

No geral, estamos tratando aqui de autores do Atlântico Norte que, a partir de suas realidades nacionais, levantaram questões universais sobre as transformações estruturais do capitalismo contemporâneo, que podem ser aplicadas ao caso brasileiro. É preciso, entretanto, que esta tarefa seja levada a cabo. Foi neste sentido que idealizamos o presente dossiê que agora trazemos ao público. No tópico seguinte, apresentaremos os artigos presentes no dossiê, assinados por alguns pesquisadores estrangeiros, mas também por alguns dos principais pesquisadores e pesquisadoras brasileiros que têm feito o esforço sistemático de sintetizar teoria e pesquisa empírica, pensando especialmente a partir do contexto brasileiro.

\section{Multiplicidade de interpretações contemporâneas do capitalismo}

No artigo de abertura do dossiê, intitulado "Capitalismo de risco. Landnahme, crise bifurcada, pandemia: chance para uma revolução sustentável?", Klaus Dörre faz uma análise dos riscos do capitalismo global a partir de sua teoria da Landnahme capitalista. Com este conceito, o autor procura definir a lógica do capitalismo a partir de sua necessidade constante de expansão e de apropriação de um outro não capitalista. Ele define a crise atual como bifurcada, no sentido de que tanto a questão socioeconômica como a questão ecológica, radicalizadas no contexto atual, colocam especialmente os países ricos diante de um dilema inevitável, a saber, a necessidade de uma revolução sustentável. Por fim, o autor utiliza este raciocínio

18. Por ser uma tradução do original publicado em alemão, este artigo está presente apenas na versão do dossiê publicada online pela Sociedade e Estado $<$ https://periodicos. unb.br/index. php/sociedade/ index>, não estando presente na versão do dossiê reproduzida pela SCiELO, que não publica traduções. para pensar a pandemia e defender uma sociologia pública que nos forneça instrumentos analíticos para evitar o desfecho do capitalismo de risco ${ }^{18}$.

Boike Rehbein, por sua vez, no artigo "Capitalism and inequality", vai fazer uma reconstrução teórica e histórica dos conceitos de capitalismo e desigualdade. Para o autor, o capitalismo em seu formato desenvolvido na Europa ocidental tem muito mais a ver com o crime organizado do que com um sistema de leis naturais. Esta realidade pode ser vista, por exemplo, na privatização das finanças e na brutalidade e ilegalidade do colonialismo, tema ao qual Rehbein vai dedicar uma importante parte de seu texto e argumentação. A ideia mais provocativa do autor é que o objetivo central do capitalismo não é a acumulação de riquezas em si, mas sim um objetivo político, ou seja, atualizar e perpetuar a dominação social. Para tanto, ele vai mostrar, com embasamento histórico, que a dominação no capitalismo difere das formas de dominação anteriores exatamente por que ela é construída através da 
acumulação de riquezas, o que não se mostra como tal. Esta realidade do capitalismo global pode ser vista, por exemplo, na relação assimétrica entre as nações que se monta com o colonialismo e se perpetua até os dias atuais. Ademais, Rehbein vai fazer uma importante distinção analítica entre classes econômicas e classes sociais, aspecto este central de toda a sua análise, na intenção de compreender como a desigualdade realmente se reproduz no capitalismo moderno.

Com o título provocativo "Do tempo escolhido aos fins do sono: tempo de trabalho e renda básica no capitalismo", Josué Pereira da Silva faz uma reconstrução histórico-teórica dos debates sobre a redução do tempo de trabalho e da renda básica, chamando atenção para a passagem da utopia do $3 \times 8$ - oito horas de sono, oito horas de trabalho e oito horas de lazer -, que inspirou as lutas pelas oito horas de trabalho, para a distopia do 24/7, na qual os indivíduos estão conectados o tempo todo, todos dias, tornando imperceptível a separação entre o tempo de trabalho e os demais tempos da vida. Sem falar que o 24/7 coloca em xeque o sono, último refúgio de resistência à lógica da mercantilização. Ao tomar como base as teorias de Karl Marx e André Gorz para discutir os temas do tempo de trabalho e da renda básica, Silva analisa como o neoliberalismo, com a máxima do Estado mínimo "que só precisa ser mínimo quando se refere à proteção dos mais vulneráveis", levou ao aumento da pobreza e das desigualdades sociais. A crise do capitalismo de 2008 deixou evidente a quem o Estado mínimo serve, uma vez que o Estado foi convocado a salvar a globalização capitalista e, tão logo o mercado se recuperou, prontamente, voltou a defender a máxima da autorregulação e das políticas de austeridade. Mesmo não pretendendo fazer uma análise de conjuntura, o autor afirma que a pandemia do coronavírus não só escancara as desigualdades sociais e assimetrias de classe, como também evidencia os problemas do desmantelamento das redes de proteção social. E aí não só somos chamados a reconhecer a importância do Sistema Único de Saúde (SUS), como também da garantia de uma renda básica para boa parte da população. Apesar de reconhecer que o discurso hegemônico das elites é de reafirmação da ode do livre mercado e do Estado mínimo, Josué vê uma brecha para que a ideia de uma renda básica se coloque no espectro político para além de uma ajuda emergencial.

Na sequência, Cinara Rosenfield e Thays Wolfarth Mossi discutem as novas configurações do mercado de trabalho em tempos de "uberização". No artigo "Trabalho decente no capitalismo contemporâneo: dignidade e reconhecimento no microtrabalho por plataformas", as autoras analisam o relatório feito pelo Bureau International do Trabalho (BIT) sobre a novidade, os problemas e os desafios do trabalho por plataformas digitais geridas por algoritmos. Uma das características do trabalho por plataformas é o estabelecimento de relações de trabalho triangu- 
lares entre trabalhador, plataforma e clientes, nas quais se radicalizam as noções de alienação e exploração do trabalho típicas do taylorismo, ao mesmo tempo em que se criam novas formas de organização produtiva que tornam ainda mais difícil a mensuração e o reconhecimento do valor do trabalho. O microtrabalho se caracteriza pela realização de tarefas solicitadas pelos clientes às plataformas, que contratam os trabalhadores para a execução dessas atividades, sem proteção social e vínculo trabalhista ou com um projeto maior. A ideia é que as plataformas façam a intermediação entre o cliente e o trabalhador, que é contratado por tarefa ao minuto. A precarização do trabalho fica evidente pela ausência de proteção social, de vínculo trabalhista, e pelas relações assimétricas entre clientes e trabalhadores. Os clientes podem se recusar a pagar por um determinado trabalho por achar que o produto entregue não está à altura de suas pretensões, sem precisar justificar as razões de sua recusa. Os trabalhadores, por sua vez, arcam sozinhos com o ônus do trabalho - a incerteza quanto aos rendimentos, o investimento no instrumento de trabalho, acesso à internet e ausência de qualquer forma de proteção coletiva (proteção social, regulação do tempo e das condições de trabalho, negociação coletiva, dentre outras). O argumento desenvolvido pelas autoras é que o relatório do BIT, ao elencar os componentes da precarização do microtrabalho e apresentar remédios a serem adotados para constituir uma agenda de reivindicações que possa garantir um trabalho decente nas plataformas digitais, desconsidera a dimensão moral do trabalho, que é anterior às reivindicações representativas e redistributivas apontadas pelo relatório. Para isso, as autoras propõem uma ampliação da noção de justiça social, articulando insights do pensamento de Alain Supiot, Nancy Fraser e Axel Honneth.

Ao levar adiante a discussão sobre o mercado de trabalho na atualidade, Jacob Carlos Lima, em seu artigo "Globalização periférica e a ressignificação dos lugares", examina as novas configurações do trabalho decorrentes de reestruturação industrial, ocorrida desde os anos de 1990, investigando os efeitos da inserção de regiões periféricas do Nordeste à lógica da produção capitalista global. O autor discute as mudanças geradas em territórios sem tradição industrial e trabalho organizado, com economia estagnada, ou cujo motor da economia são as atividades agrícolas tradicionais com sua integração a um quadro de expansão de mercados globais. Ao constatar que o local se integra ao global de diferentes formas, complementares e heterogêneas, o autor reflete sobre esse processo, examinando três setores produtivos instalados em sub-regiões do Nordeste - setor de confecção, de produção de software e da indústria automobilística. A reconfiguração social e cultural do local é avaliada a partir da terceirização da produção têxtil na região do Seridó, no Rio Grande do Norte; da produção de software em João Pessoa, na Paraíba; e do deslocamento da indústria fordista para o interior, mais especificamen- 
te, para Goiana, em Pernambuco. Lima demonstra como a globalização é múltipla, num mesmo território coexistem diversas formas de emprego - formais, informais e precários -, sendo as práticas sociais transformadas por processos sociais mais amplos, sem perder suas especificidades.

Por fim, Thomas Kühn, Daniela Gomes Alcoforado e Miriam Leite Farias, no artigo intitulado "New normalcy? Consumption and identity between reproduction of social inequalities and social transformation in Brazil", realizam uma análise sobre o "novo normal", termo em evidência atualmente, e sua relação com o consumo e as mudanças de narrativas na identidade pessoal. Para tanto, recorrem a perspectivas teóricas de autores como Erich Fromm e Thomas Kühn. O estudo analisou as narrativas de mudanças de consumo apresentadas por brasileiros entrevistados no atual período de distanciamento social. Como conclusão, o artigo argumenta que a pandemia estimula as pessoas a refletirem com responsabilidade sobre seu consumo, mas também destaca como o consumo contribui para a reprodução da desigualdade social, levando a polarizações dentro da sociedade.

\section{Referências}

ARRUZZA, Cinzia; BHATTACHARYA, Tithi; FRASER, Nancy. Feminismo para 99\%: Um manifesto. São Paulo: Boitempo, 2019.

ANTUNES, Ricardo. Adeus ao trabalho? Ensaio sobre as metamorfoses e a centralidade do mundo do trabalho. São Paulo: Cortez, 2000.

BECK, Ulrich. A metamorfose do mundo. Novos conceitos para uma nova realidade. Rio de Janeiro: Zahar, 2018.

. Die Neuvermessung der Ungleichheit unter den Menschen. Frankfurt am Main (DE): Suhrkamp, 2008.

. Schöne neue Arbeitswelt. Frankfurt am Main (DE): Suhrkamp, 2007.

. Risikogesellschaft. Auf dem Weg in eine andere Moderne. Frankfurt am Main (DE): Suhrkamp, 1986.

BOLTANSKI, Luc; CHIAPELLO, Ève. O novo espírito do capitalismo. São Paulo: Martins Fontes, 2009.

BOLTANSKI, Luc; ESQUERRE Arnauld. Enrichment. A critique of commodities. Cambridge (UK): Polity press, 2020. 
BROWN, Wendy. American nightmare: neoliberalism, neoconservatism, and de-democratization. Political Theory, v. 34, n. 6, p. 690-714, 2006.

CASTEL, Robert. Metamorfoses da questão social. Uma crônica do salário. Petrópolis (RJ): Vozes, 1998.

COLLINS, Randall. The end of middle-class work: No more escapes. In: WALLERSTEIN, Immanuel; COLLINS, Randall; MANN, Michael; DRERLUGUIAN, Georgi; CALHOUN, Craig. Does capitalism have a future? Oxford (UK): Oxford University Press, 2013

$\mathrm{CROUCH}$, Colin. The strange non-death of neoliberalism. Cambridge (UK): Polity, 2011.

FRASER, Nancy. Crise de legitimação? Sobre as condições políticas do capitalismo financeirizado. Cadernos de Filosofia Alemã, v. 23, n. 2, p. 153-188, Jul./Dez. 2018.

Por trás do laboratório secreto de Marx. Por uma concepção expandida do capitalismo. Direito \& Práxis, v. 6, n. 10, p. 704-728, 2015a.

. Las contradicciones del capital y los cuidados. New Left, v. 100, p. 111-132, Sep./Oct. 2015b.

FRASER, Nancy; JAEGGI, Rahel. Capitalismo: Una conversación desde la Teoría Crítica. Madrid: Morata, 2019.

GILL, Stephen. New constitutionalism, democratisation and global political economy. Pacifica Review, v. 10, n. 1, p. 23-38, 1998.

GORZ, André. O imaterial. Conhecimento, valor e capital. São Paulo: Editora Annablume, 2005.

. Misérias do presente, riqueza do possível. São Paulo: Annablume, 2004.

Abschied vom Proletariat. Jenseits des Sozialismus. Frankfurt am Main (DE): Europäische Verlagsanstalt, 1980.

HONNETH. Axel. O direito da liberdade. São Paulo: Martins Fontes, 2015.

LESSENICH, Stephan. Neben uns die Sintflut. Wie wir auf Kosten anderer Leben. München (DE): Piper, 2018.

NACHTWEY, Oliver. Die Abstiegsgesellschaft. Über das Aufbegehren in der regressiven Moderne. Frankfurt (DE): Suhrkamp, 2016. 
NECKEL, Sighard. Die Refeudalisierung des modernen Kapitalismus. In: BUDE, Heinz; STAAB, Philipp. Kapitalismus und Ungleichheit. Die neuen Verwerfungen. Frankfurt (DE); New York: Campus, 2016.

OFFE, Claus. Capitalismo desorganizado. São Paulo: Brasiliense, 1994.

PIKETTY, Thomas. O capital no século XXI. Rio de Janeiro: Intrínseca, 2014.

SANTOS, Boaventura de Sousa. Coronavírus: Tudo o que é sólido desmancha no ar. "Dossiê Boitempo Covid 19". Disponível em: <https://blogdaboitempo.com. $\mathrm{br} / 2020 / 04 / 02 / c o r o n a v i r u s-t u d o-o-q u e-e-s o l i d o-d e s m a n c h a-n o-a r />$. Acesso em: 01 Ago. 2020.

SENNETT, Richard. A cultura do novo capitalismo. Rio de Janeiro; São Paulo: Record, 2015.

A corrosão do caráter. Rio de Janeiro: Record, 2006.

SLEE, Tom. Uberização. A nova onda do trabalho precarizado. São Paulo: Editora Elefante, 2019.

SOUZA, Jessé. A construção social da subcidadania. Rio de Janeiro; Belo Horizonte: Iuperj; Editora UFMG, 2003.

STIGLITZ, Joseph. After neo-liberalism, progressive capitalism. Project Syndicate, 2019. Disponível em: <https://www.project-syndicate.org/commentary/after-neoliberalism-progressive-capitalism-by-joseph-e-stiglitz-2019-05>. Acesso em: 01 Ago. 2020

STREECK, Wolfgang. Tempo comprado: A crise adiada do capitalismo democrático. São Paulo: Boitempo, 2018.

How will capitalism end? Londres; New York: Verso, 2016.

SUMMERS, Lawrence. US economic prospect: secular stagnation, hysteresis, and the zero lower bound. Business Economics, v. 49, n. 2, p. 65-73, 2014.

WALLERSTEIN, Immanuel. The modern world-system. New York: Academic Press, 1976.

WALLERSTEIN, Immanuel; COLLINS, Randall; MANN, Michael; DRERLUGUIAN, Georgi; CALHOUN, Craig. Does capitalism have a future? Oxford (UK): Oxford University Press, 2013. 


\section{Sites consultados}

$<$ https://exame.com/economia/apps-como-uber-e-ifood-sao-fonte-de-renda-de-quase-4-milhoes-de-pessoas/>. Acesso em: 26 Ago. 2020.

<https://piaui.folha.uol.com.br/materia/como-vai-acabar-o-capitalismo/>. Acesso em: 01 Ago. 2020.

<https://blogdaboitempo.com.br/dossies-tematicos/dossie-coronavirus/>. Acesso em: 01 Ago. 2020.

\section{Filme}

LOACH, Ken. "Você não estava aqui". Grã-Bretanha, 2019, independente, 101 min. 